\title{
Clinical usefulness of ventilator associated events in predicting ventilator associated pneumonia
}

\author{
Amarja Ashok Havaldar ${ }^{1}$, Natarajan Rajgopalan², Vipin Gupta ${ }^{3}$, Manjunath $\mathrm{PH}^{4}$ \\ ${ }^{1}$ Department of Critical Care Medicine, St Johns Medical College, Bangalore, India \\ ${ }^{2}$ Department of Pulmonary Medicine, Orlando VA Medical Center, US \\ ${ }^{3}$ Department of Pulmonology, Sarvodaya Hospital, Faridabad, India \\ ${ }^{4}$ Department of Pulmonary Medicine, Mazumdar Shaw Medical Centre, Narayana Health, India
}

DOI: $10.3396 /$ ijic.v16i3.018.20

\begin{abstract}
Ventilator-associated pneumonia (VAP) is the most common nosocomial infection in intensive care unit (ICU) patients. Traditionally the clinical pulmonary infection score (CPIS) has been used in the diagnosis of VAP. There is no firm agreement among critical care and infectious disease specialists regarding the diagnosis of VAP. The aim was to study the association between new conditions, ventilator-associated conditions (VAC) and infection related ventilator- associated complications (IVAC) and VAP and whether if any of these precedes the diagnosis of VAP by CPIS.
\end{abstract}

A prospective observational study was conducted from January 2014 to 31st March 2014 (IEC ref 2014/226A). Inclusion criteria of our study were patients requiring invasive mechanical ventilation for $>2$ calendar days. VAC and IVAC were diagnosed based on Centers for Disease Control and Prevention criteria. VAP was diagnosed using modified CPIS score if the score was $>6$.

One hundred consecutive patients were screened for the study. Thirteen patients were excluded. Out of 87 patients, 15 developed VAC of whom 13 developed IVAC, and seven patients developed VAP as per CPIS. Diagnosis of VAC preceded diagnosis of VAP in three patients. No temporal relationship was noted in four patients.

This study has shown significant association between VAC, IVAC and modified CPIS criteria for VAP. From our study, there is a suggestion of VAC preceding the diagnosis of VAP by CPIS criteria. However, this needs further validation from the future studies with a larger number of patients.

Keywords: ventilators, complications, associated conditions, ventilator-associated pneumonia, India

\section{Corresponding author:}

Dr Amarja Ashok Havaldar

MICU, St John's Medical College, Kormangala, Bangalore -560034, India

amarjahavaldar@rediffmail.com 


\section{Introduction}

Ventilator-associated pneumonia (VAP) is one of the most serious and common nosocomial infections in the intensive care unit (ICU). ${ }^{1,2}$ Development of VAP is associated with increased length of ICU stay and mortality. Timely diagnosis of VAP is important and essential in order to plan further management. ${ }^{1-4}$ Traditionally the diagnosis of VAP has been made with the clinical pulmonary infection score (CPIS) criteria. $^{5}$ The sensitivity and specificity of CPIS has been questioned. It has been proposed that early diagnosis of VAP may reduce the unfavorable outcomes of patients with VAP in the critical care setting. Also, in certain countries such as the United States, reimbursements for VAP-related expenses are routinely denied by third party insurances as a punitive action. ${ }^{6,7}$

The US Centers for Disease Control and Prevention (CDC) proposed a new surveillance system for VAP, which included ventilator-associated conditions (VAC), infection related ventilator-associated complications (IVAC), and possible and probable pneumonia. These surveillance definitions were suggested by CDC for public reporting and interfacility comparisons, and VAP was used only in internal quality improvement. $5,8,9$

After the development of this new surveillance system there have been many studies trying to evaluate the utility of this newer system of reporting and comparing it with existing CPIS criteria. ${ }^{10-15}$

There are certain changes as per the 2015 CDC update, in which possible and probable VAP are combined into one as against earlier CDC update. There is also specific mention about the list of pathogens excluded as a cause for VAP. Special mention of episodes on mechanical ventilation (EMV), ventilator free days and airway pressure release ventilation (APRV) days. ${ }^{16,17}$ For analysis of data these changes were taken into account.

The aim of our study was to evaluate the association between diagnosis of VAC, IVAC and VAP in our subset of patients.

\section{Materials and Methods}

After obtaining institutional ethical committee approval (ref 2014/226A), this study was conducted in the medical ICU of a tertiary care center (Mazumdan Shaw Medical Centre, Narayana Health, Bangalore) for a period of 3 months (1st January 2014 to 31st March 2014). Inclusion criteria for the study were patients requiring invasive mechanical ventilation support for $>2$ calendar days. Patients transferred from other healthcare facilities and patients unlikely to survive $>48$ hours were excluded from the study.

VAC was defined as per the CDC guidelines as increase in $\mathrm{FIO} 2$ by $20 \%$ or increase in positive end expiratory pressure (PEEP) of $3 \mathrm{~cm} \mathrm{H} 2 \mathrm{O}$ after 2 calendar days of stability. Diagnostic criteria for IVAC included patients with VAC who developed temperature $>38^{\circ} \mathrm{C}$ or $<36^{\circ} \mathrm{C}$, or WBC count $>12000 / \mathrm{mm} 3$ or $<4000 / \mathrm{mm} 3$ and commencement of a new antimicrobial agent(s) and their continuation for $>4$ calendar days. VAP was diagnosed by modified CPIS score, which includes temperature, leucocyte count, tracheal secretions, oxygenation and chest radiograph findings. The modified CPIS score does not include microbiology or culture as against CPIS score. Patients with modified CPIS score $>6$ were diagnosed as having VAP. In our study microbiological data were not included in CPIS calculations. Patients were followed up until ICU discharge.

Statistical analysis was done using STATA 13 (StataCorp, College Station, TX). Continuous variables were expressed as mean + SD (standard deviation) or median IQR (interquartile range). Continuous variables were analyzed by ' $\mathrm{t}$ ' test and categorical variables were analyzed by ' $\chi 2$ ' test. A standard $95 \%$ confidence limit and a $p$ value at 0.05 were used for assessing statistical significance.

\section{Results}

One hundred consecutive patients were screened for the study. Out of these 13 patients were excluded (1 patient was transferred to another healthcare facility, 6 patients expired, and 6 patients got extubated within $48 \mathrm{~h})$. Among the baseline characteristics, mean APACHE II score was 20 (SD 6.04) (Table I).

Out of 87 patients, 15 satisfied criteria for diagnosis of VAC, 13 for IVAC, and 7 for VAP by CPIS. Figure 1 shows seven cases of VAP and the day on which VAC, IVAC and VAP diagnosis was made. Diagnosis of VAC 
Table I. Baseline characteristics of patients with ventilator-associated condition (VAC), infection-related ventilator-associated complication (IVAC), and ventilator-associated pneumonia (VAP)

\begin{tabular}{|c|c|c|c|c|c|c|c|c|c|c|}
\hline$\frac{\frac{0}{2}}{\frac{\pi}{\pi}}$ & m. & $\frac{\infty}{0}$ & ڤొ & 号 & o̊ & $\stackrel{\sim}{\stackrel{0}{0}}$ & ०. & ס & 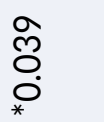 & \\
\hline 은 定 & 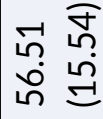 & 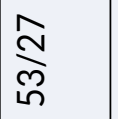 & 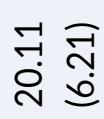 & i) & 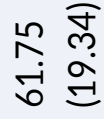 & 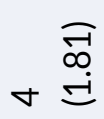 & 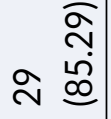 & 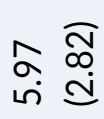 & 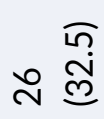 & \\
\hline 迹E & 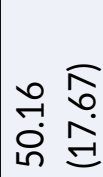 & $\underset{\text { in }}{N}$ & 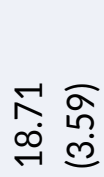 & $\begin{array}{l}\widehat{o} \\
\hat{N} \\
\stackrel{d}{d} \\
\vec{d} \\
\infty \\
\infty\end{array}$ & 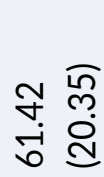 & 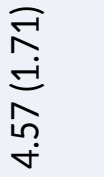 & 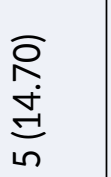 & 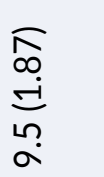 & $\underset{n}{\stackrel{\vec{J}}{\vec{S}}}$ & \\
\hline$\frac{\frac{0}{7}}{\frac{\pi}{20}}$ & $\stackrel{\substack{n \\
m}}{0}$ & $\begin{array}{l}\infty \\
\infty \\
\sim \\
0 \\
0\end{array}$ & 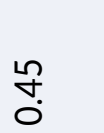 & $\begin{array}{l}-1 \\
8 \\
0 \\
0 \\
*\end{array}$ & $\stackrel{ }{\circ}$ & 㟔 & $\begin{array}{l}0 \\
0 \\
0 \\
0 \\
* \\
*\end{array}$ & రి & 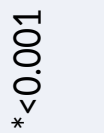 & \\
\hline 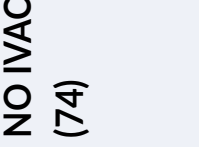 & 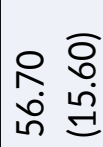 & $\underset{\text { in }}{\stackrel{N}{-1}}$ & 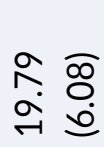 & 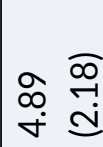 & 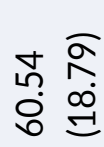 & 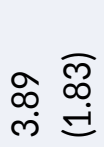 & 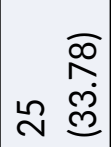 & ô & 워 & \\
\hline$\stackrel{\text { M }}{\underline{I}}$ & 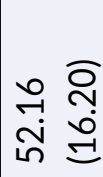 & $\frac{0}{n}$ & 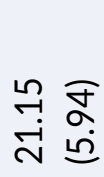 & $\begin{array}{l}\frac{a}{a} \\
\stackrel{9}{m} \\
\infty\end{array}$ & 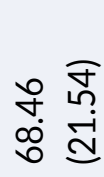 & 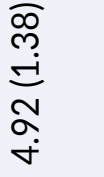 & $\begin{array}{l}\bar{a} \\
\text { ạ } \\
a \\
a \\
a\end{array}$ & $\begin{array}{l}\widehat{\infty} \\
\stackrel{j}{\sim} \\
\infty \\
\infty \\
\infty\end{array}$ & 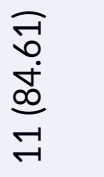 & \\
\hline$\frac{\frac{0}{3}}{\frac{\pi}{\pi}}$ & f. & స్ & ণั. & $\begin{array}{l}-1 \\
8 \\
0 \\
0 \\
* \\
*\end{array}$ & $\stackrel{\bullet}{\stackrel{7}{0}}$ & $\stackrel{ }{-1}$ & $\begin{array}{l}\infty \\
0 \\
0 \\
0 \\
0\end{array}$ & $\begin{array}{l}\text { ठ̊ } \\
\text { ○ }\end{array}$ & 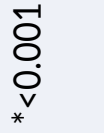 & \\
\hline 花 & 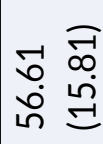 & స̃ & 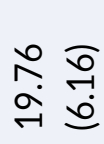 & $\begin{array}{ll}\infty & \widetilde{\infty} \\
\infty & \stackrel{\sim}{\sim}\end{array}$ & 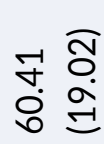 & $\begin{array}{l}\text { \% } \\
\stackrel{0}{\alpha} \\
\dot{m}\end{array}$ & 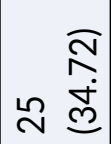 & 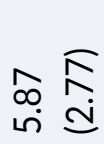 & $\underset{\stackrel{\mathfrak{n}}{\stackrel{\infty}{\sim}}}{\stackrel{\infty}{\sim}}$ & \\
\hline 足 & 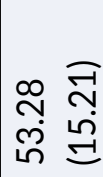 & $\underset{\infty}{\infty}$ & $\begin{array}{l}\stackrel{M}{\rightarrow} \\
\stackrel{n}{\sim} \\
\end{array}$ & $\begin{array}{l}\widetilde{ָ} \\
\mathfrak{n} \\
\\
\tilde{n} \\
\end{array}$ & 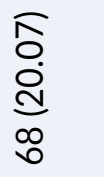 & 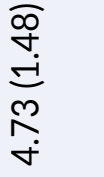 & $\frac{\overline{0}}{8}$ & 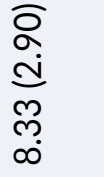 & $\begin{array}{l}0 \\
b \\
0 \\
\infty \\
\stackrel{0}{\oplus}\end{array}$ & \\
\hline 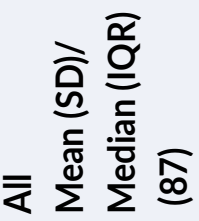 & 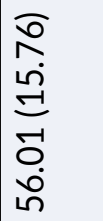 & 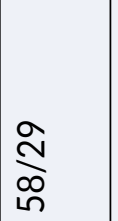 & $\begin{array}{l}\text { वे. } \\
\text { ठ } \\
\text { ○े }\end{array}$ & 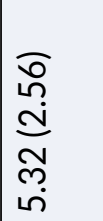 & 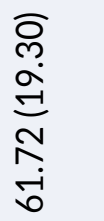 & 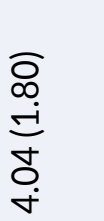 & 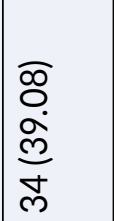 & 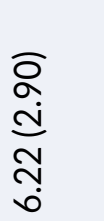 & 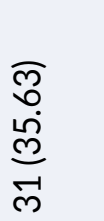 & \\
\hline 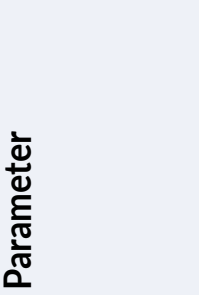 & $\underset{<}{\stackrel{8}{\alpha}}$ & 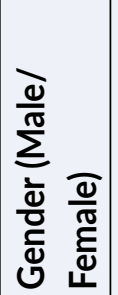 & 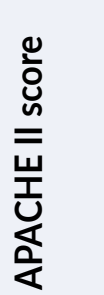 & 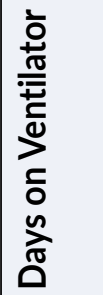 & 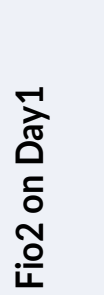 & 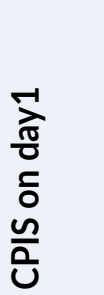 & 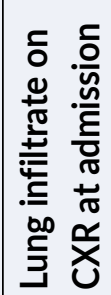 & $\frac{\partial}{\tilde{U}}$ & 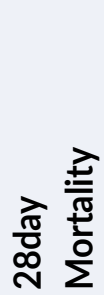 & 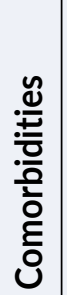 \\
\hline
\end{tabular}


VAC: ventilator-associated condition; IVAC: infection-related ventilator-associated complication; VAP: ventilatorassociated pneumonia; CPIS: Clinical Pulmonary Infection Score; CXR: chest X-ray; LOS: length of stay; ICU: intensive care unit; CVS: cardiovascular disease; RS: respiratory disease; CNS: neurologic disease

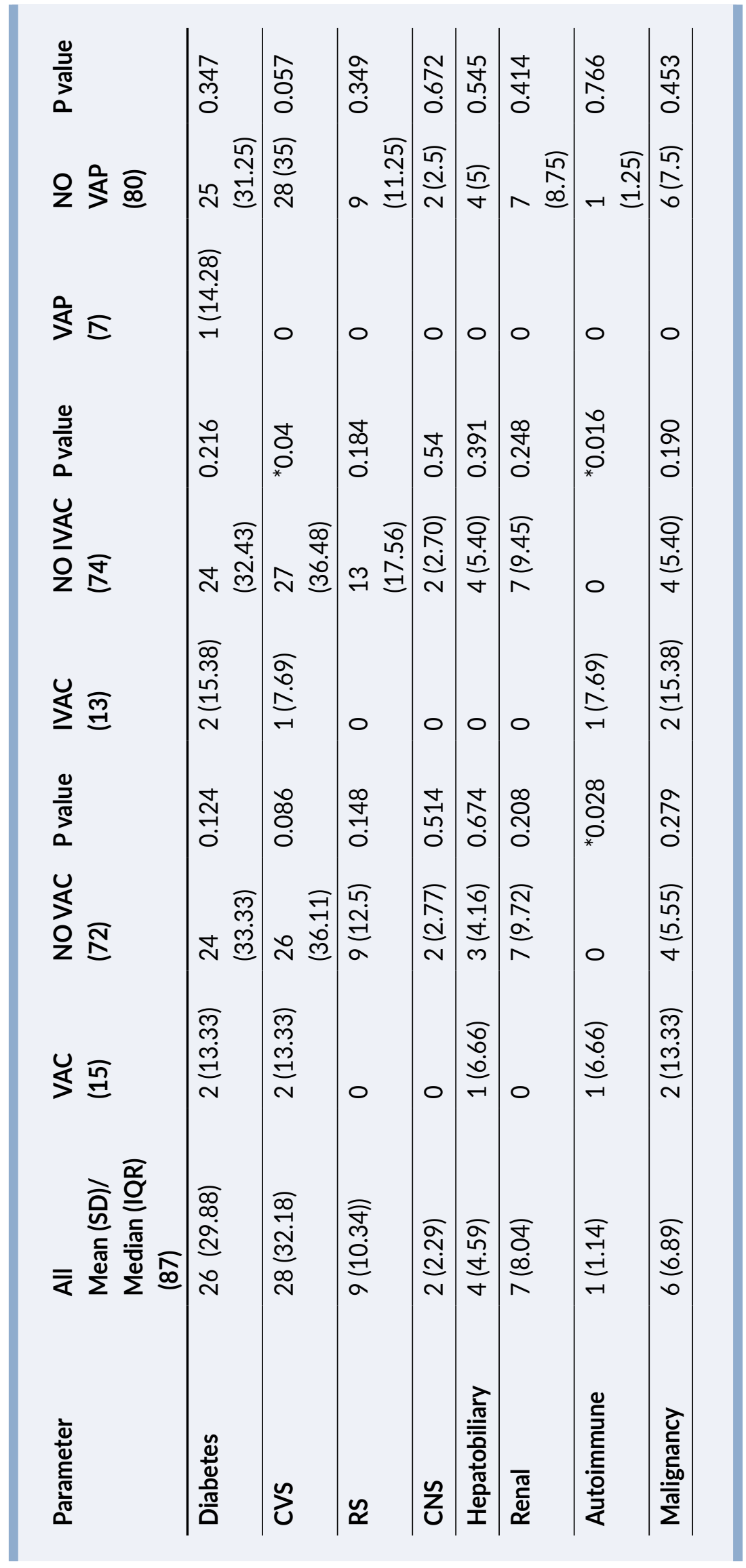


preceded diagnosis of VAP by two days in one patient (case no.5), and by three days in another patient. In one patient (case no.4), VAC preceded VAP by five days (case no.6). Among four patients (cases no. $1,2,3,7)$ no temporal association was noted between VAC and VAP, as shown in Figure 1. Baseline mortality was around $31 \%$. Patients who developed VAC, IVAC or VAP had higher mortality and more ventilator days (Table I).

Among 13 patients with IVAC, 11 patients were classified as pneumonia. One patient who satisfied the criteria for IVAC was subsequently diagnosed as tumor lysis syndrome. In two patients diagnosed as IVAC by CDC classification, diagnosed as VAP as per the CPIS, lung infiltrates were not present on chest $X$ ray and hence should accurately be diagnosed as ventilator associated tracheobronchitis (VAT) (Figure 2).

Fisher's exact test was performed to look for the association between VAC, IVAC and VAP. There was a statistically significant association among VAC and VAP, $\chi 2$ (1) 36.54, $p<0.001$ and among IVAC and VAP, $x 2$ (1) 43.33, $p<0.001$. Among 15 VAC patients 7 developed VAP (46.66\%), and among 13 IVAC patients 7 developed VAP (53.84\%) (Table II, III).

\section{Discussion}

This prospective observational study has shown significant association between VAC, IVAC and VAP. The incidence of VAC was $17.24 \%$. Out of 15 patients with VAC, 13 (86.66\%) developed IVAC and 7 patients

Table II. Association between ventilator-associated condition (VAC) and ventilator-associated pneumonia (VAP)

VAC: ventilator-associated condition; VAP: ventilator-associated pneumonia; $0=$ absent, $1=$ present

\begin{tabular}{llll} 
VAC & VAP 0 & VAP 1 & Total \\
\hline 0 & 72 & 0 & 72 \\
\hline 1 & 8 & 7 & 15 \\
\hline & 80 & 7 & 87 \\
\hline$P=*<0.001$ & & & \\
\hline
\end{tabular}

*significant $\mathrm{p}<0.05$

Table III. Association between infection-related ventilator-associated complication (IVAC) and ventilatorassociated pneumonia (VAP)

\begin{tabular}{|c|c|c|c|}
\hline IVAC & VAP 0 & VAP 1 & Total \\
\hline 0 & 74 & 0 & 74 \\
\hline \multirow[t]{2}{*}{1} & 6 & 7 & 13 \\
\hline & 80 & 7 & 87 \\
\hline$P={ }^{*}<0.001$ & & & \\
\hline
\end{tabular}

IVAC: infection-related ventilator-associated complication; VAP: ventilator-associated pneumonia; $0=$ absent, 1 = present

*significant $p<0.05$ 
Figure 1. Timeline of ventilator-associated condition (VAC), infection-related ventilator-associated complication (IVAC), and ventilator-associated pneumonia (VAP)

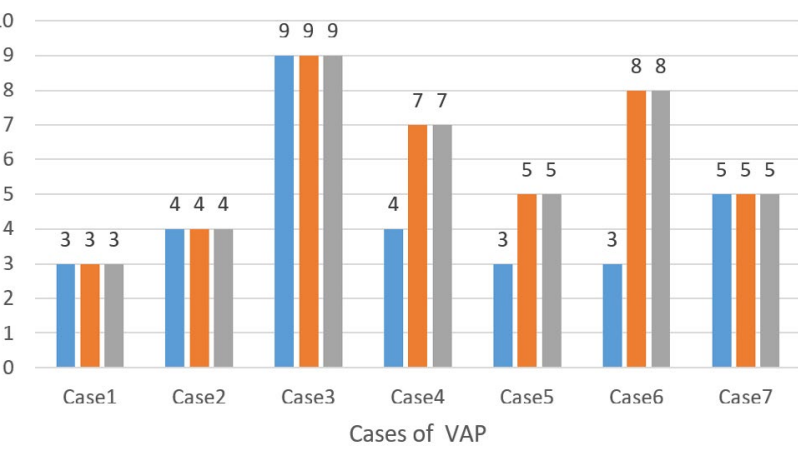

developed VAP (46.66\%). In our study there was a higher incidence of VAC and IVAC as compared with the meta-analysis data of Boyer's study. ${ }^{13,14}$

The diagnosis of VAP in the ICU can be quite challenging. Historically chest $X$-ray was used initially to diagnose VAP. The study by Wunderink et al showed that there was no good correlation between radiological signs of pneumonia with autopsy findings. ${ }^{18}$ The major limitation for using $X$ - ray is that it has nonspecific findings and abnormalities may not accurately reflect infection as a cause of $X$ ray abnormalities. There can also be inter-observer variability. Diagnosis by clinical signs and symptoms such as fever, leukocytosis can also nonspecific. Evaluation of different scoring systems has not reached any consensus in the critical care field. ${ }^{12}$

The routine CPIS score which comprises of different parameters such as fever, leukocytosis, radiological, tracheal aspirate, oxygenation and microbiology, is associated with variable sensitivity and specificity as reported in the different studies. ${ }^{6,7}$ The modified CPIS score which excludes microbiological data is also shown to have limitations. ${ }^{6,7}$

One study comparing CPIS vs. CDC criteria for different facets of VAP showed no clear advantage either in terms of reliability or specificity. Hence CDC criteria in the diagnosis of VAP has been used for surveillance purposes only. ${ }^{11}$

A multi- center study showed high predictive accuracy for ventilator associated events (VAE) with respect to tracheobronchitis but not VAP. It also showed that a differentiation between tracheobronchitis and VAP is essential as there is a significant difference in the mortality between the two conditions. ${ }^{15}$ Results of this study were consistent with the meta-analysis data by Yunzhou Fan et al., which showed VAE could not accurately and consistently detect cases of VAP. ${ }^{13}$

In our study, two patients with VAP who had no new lung infiltrates can be classified as VAT who survived, as compared with five patients with VAP who died. In our study more severe VAP cases were captured with compromised oxygenation for $>24 \mathrm{hr}$ as reflected by serial CPIS.

There were certain limitations to our study. It was a single center study. Results of the statistical analysis on our data should be taken in the context of low number of patients studied. In the exclusion criteria, we excluded patients who died or extubated within 48hrs. Ideally the cut off should have been 96 hours to correctly identify VAE episodes. ${ }^{13}$

However, the present study did find a statistically significant association between VAE and 28-day mortality. These results were in accordance with study by Boyer et al. ${ }^{14}$ Possible reason for such results could be use of ultrasonography was already in place and that could have minimized interobserver variation in interpreting CXR findings, allthough use of ultrasonography was not a part of study methodology.

The CDC criteria for diagnosis of VAE could alert the possibility of developing IVAC.VAE is a useful tool for surveillance purposes but cannot be used for diagnosis of VAP. In our opinion the modified CPIS score is still useful in the diagnosis of VAP. Nonetheless it is important to recognize these

Figure 2. Lung infiltrates and ventilator-associated pneumonia (VAP)

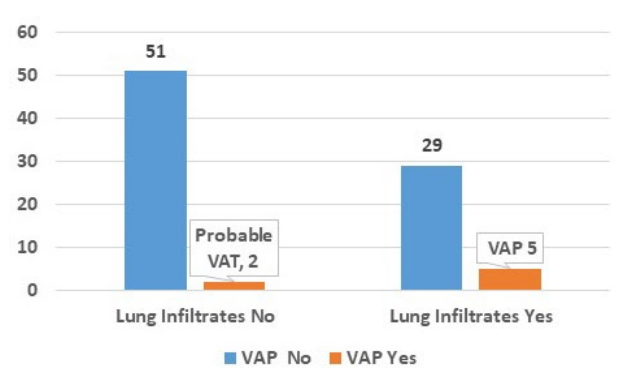

-VAP No $\square$ VAPYes 
two conditions as there is a correlation between them and 28-day mortality. There are reasons why CDC classification of VAE is not recommended for the diagnostic purposes of ventilator associated infection. VAE can be due to multiple causes such as atelectasis, pulmonary edema, pulmonary embolism, acute respiratory distress syndrome, pneumothorax and sepsis. In most cases it can be said that IVAC can identify the infective cause for VAE but the criteria including the presence of fever, change in WBC count and antibiotic change could be secondary to multiple other causes in ICU. ${ }^{19}$ Diagnosis by the modified CPIS as well as VAC have certain limitations. The CPIS score can be elevated when a patient gets admitted with community acquired pneumonia and later develops VAP. The timing of this complication then becomes difficult. Similarly, with regard to VAC it must be said that IVAC identifies only severe cases of VAP with compromised oxygenation for two calendar days and may miss less severe VAP. IVAC does not differentiate between VAP and VAT, as the management and prognosis are perhaps different. The higher mortality associated with VAE reported in the literature is again shown in our current study. ${ }^{20,21}$

\section{Conclusions}

Our study has shown a statistically significant association between VAE and VAP. The results of our study need to be validated by larger multicenter studies. ${ }^{20-22}$ Looking at recent studies use of VAE for surveillance itself is questionable and needs modifications.

\section{Declarations}

Ethics approval and consent to participate- This study was approved by Institutional Ethics Committee, ref no. $(2014 / 226 \mathrm{~A})$.

Consent for publication- Not applicable

Availability of data and material- Data are available from the authors upon reasonable request

Competing interest- The authors declare that they have no competing interest

Funding- Not applicable

\section{Acknowledgement}

The authors would like to thank Sowmya Vivek for her help in data analysis.

\section{References:}

1. Kalanuria AA, Zai W, Mirski M. Ventilator-associated pneumonia in the ICU. Critical Care 2014; 18(2): 208-215. https://doi.org/10.1186/cc13775

2. Hunter JD. Ventilator associated pneumonia. BMJ 2012; 344: e3325. https://doi.org/10.1136/bmj.e3325

3. Nair GB, Niederman MS. Ventilator-associated pneumonia: present understanding and ongoing debates. Intensive Care Med 2015; 41(1): 34-48. https://doi.org/10.1007/s00134014-3564-5

4. Rello J, Riera J, Serrano R. What's new in ventilator-associated pneumonia? Intensive Care Med 2015; 41(11): 1954-1956. https://doi.org/10.1007/s00134-015-3909-8

5. Rea-Neto A, Youssef NC, Tuche F, et al. Diagnosis of ventilatorassociated pneumonia: a systematic review of the literature. Crit Care 2008; 12(2): R56. https://doi.org/10.1186/cc6877

6. Pugin J, Auckenthaler R, Mili N, Janssens JP, Lew PD, Suter PM. Diagnosis of ventilator-associated pneumonia by bacteriologic analysis of bronchoscopic and nonbronchoscopic "blind" bronchoalveolar lavage fluid. Am Rev Resp Dis 1991; 143: 1121-1129. https://doi.org/10.1164/ajrccm/143.5_ Pt_1.1121

7. Zilberberg MD, Shorr AF. Ventilator-associated pneumonia: the clinical pulmonary infection score as a surrogate for diagnostics and outcome. Clin Infect Dis 2010; 51(Suppl 1): S131-135. https://doi.org/10.1086/653062

8. Magill SS, Fridkin SK. Improving surveillance definitions for ventilator-associated pneumonia in an era of public reporting and performance measurement. Clin Infect Dis 2012: 54(3): 378-380. https://doi.org/10.1093/cid/cir833

9. Magill SS, Klompas M, Balk R, et al. Developing a new, national approach to surveillance for ventilator-associated events. Am J Crit Care. 2013; 22(6): 469-473. https://doi.org/10.4037/ ajcc2013893

10. Safdar N, O'Horo JC, Mak R, Medow J. Agreement between the clinical pulmonary infection score and NHSN criteria for surveillance of ventilator associated pneumonia. Int J Infect Control. 2013; 9: i1. https://doi.org/10.3396/ijic.v9i1.008.13

11. Waltrick R, Possamai DS, Aguiar FP, et al. Comparison between a clinical diagnosis method and the surveillance technique of the Center for Disease Control and Prevention for identification of mechanical ventilator-associated pneumonia. Rev Bras Ter Intensiva 2015; 27(3): 260-265. https://doi.org/10.5935/0103-507X.20150047

12. Wallace FA, Alexander PD, Spencer C, Naisbitt J, Moore JA, McGrath BA. A comparison of ventilator-associated pneumonia rates determined by different scoring systems in four intensive care units in the North West of England. Anaesthesia 2015; 70(11): 1274-1280. https://doi. org/10.1111/anae.13211 
13. Fan Y, Gao F, Wu Y, Zhang J, Zhu M, Xiong L. Does ventilatorassociated event surveillance detect ventilator-associated pneumonia in intensive care units? A systematic review and meta-analysis. Crit Care 2016; 20(1): 338-350. https://doi. org/10.1186/s13054-016-1506-z

14. Boyer AF, Schoenberg N, Babcock H, McMullen KM, Micek $\mathrm{ST}$, Kollef $\mathrm{MH}$. A prospective evaluation of ventilatorassociated conditions and infection-related ventilatorassociated conditions. Chest 2015; 147(1): 68-81. https://doi. org/10.1378/chest.14-0544

15. Ramírez-Estrada S, Lagunes L, Peña-López Y, et al. Assessing predictive accuracy for outcomes of ventilator-associated events in an international cohort: the EUVAE study. Intensive care medicine 2018; 44(8): 1212-1220. https://doi. org/10.1007/s00134-018-5269-7

16. Timsit JF, Esaied W, Neuville M, Bouadma L, Mourvllier B. Update on ventilator-associated pneumonia F1000Res 2017; 6 (F1000 Faculty review): 2061. https://doi.org/10.12688/ f1000research.12222.1
17. McMullen KM, Boyer AF, Schoenberg N, Babcock HM, Micek ST, Kollef MH. Surveillance versus clinical adjudication: differences persist with new ventilator-associated event definition. Am J Infect Control 2015; 43(6): 589-591. https:// doi.org/10.1016/j.ajic.2015.03.004

18. Wunderink RG, Woldenberg LS, Zeiss J, Day CM, Ciemins J, Lacher DA. The radiologic diagnosis of autopsy proven ventilator-associated pneumonia. Chest 1992; 101(2): 458463. https://doi.org/10.1378/chest.101.2.458

19. Chastre J, Luyt CE. Does this patient have VAP? Intensive Care Med 2016; 42(7): 1159-1163. https://doi.org/10.1007/ s00134-016-4239-1

20. Klompas M, Kleinman K, Murphy MV. Descriptive epidemiology and attributable morbidity of ventilatorassociated events. Infect Control Hosp Epidemiol 2014; 35(5): 502-510. https://doi.org/10.1086/675834

21. Klompas M, Berra L. Should ventilator-associated events become a quality indicator for ICUs? Respiratory care 2016; 61(6): 723-736. https://doi.org/10.4187/respcare.04548

22. Muscedere J, Sinuff T, Heyland DK, et al. The clinical impact and preventability of ventilator-associated conditions in critically ill patients who are mechanically ventilated. Chest 2013; 144(5): 1453-1460. https://doi.org/10.1378/ chest.13-0853 